\title{
Thinking outside the Box to Get inside the Black Box: Alternative Epistemology for Dealing with Financial Innovation
}

This paper seeks to ignite debate surrounding the computerization and change in organizing financial markets and, due to the emergence of trading algorithms, investigates those as disruptive innovation and its side effects. First, we frame the computerization of financial markets as disruptive innovation. Second, we analyze how an extension of a disruptive innovation generates latent effects that contradict the ori- ginal principles. Third, we argue the necessity to explicitly consider the epistemological nature of financial innovations. This leads to our conclu- sion that there is a necessity to extend the epistemological dimension of financial innovation, in order to think outside the box to get inside the black box of financial innovation.

Key words Black box; disruptive innovation; epistemology; financial innovation; financial markets; flash crashes

\section{Introduction}

Financial markets and financial innovation discourses are organized around value creation (Souleles 2017). However, in a number of unanticipated events, value has been destroyed rather than created (Condliffe 2016). Flash crashes are telling examples of such situations. On 7 July 2017, CNBC 'reported another mysterious flash crash'. This was at least the second one within a couple of months, explicated by the flash crash on silver (Javier and Barton 2017). This flash crash was preceded by the sterling flash crash (Long 2016). For the sterling flash crash, The Economist financial editor investigated what could have caused it, ruling out human error, and pointing to computer systems being involved. Indeed, they analyzed the speeches of the politicians, which send negative signals to the markets that started selling the pound at a very high rate (Long 2016). The fact that flash crashes are happening not only in the equity market and in the bond market but also in the currency market is evidence of the expansion of the phenomenon.

A financial market flash crash is a very rapid and deep fall in a security price (Schinckus 2017). They cause concerns in the way markets operate, as they have systemically altered the nature of access to financial markets (Lenglet and Joeri2016), and they remain unanticipated, surprising and unmanageable events causing domino effects in the economy (Lange, Lenglet, and Seyfert 2016). At the moment, there are no viable solutions (Senior Supervisors Group 2015) or proposals on how to prevent them, or how to manage these events (Borch 2016).

There are no tools to forecast exactly when a flash crash will arise: as a result, researchers' energy is currently focused on regulating high-frequency trading algorithms (Coombs 2016). Hitherto, flash crashes cause such widespread concern and economic losses that when regulators identify a flash crash happening they simply switch off the market (Schinckus 2018), since the specific details of the sociomaterial management of order flows are unknown to the regulators (Lenglet and 
Joeri 2016) and there are no well-defined regulations (Coombs 2016). Heeding MacKenzie's (2003) advice to open up the black box, we analyze the construction of algorithms, conceiving them as a disruptive innovation, reflecting on why their evolution from computerization of the financial market to trading algorithms caused epistemological issues that have not been solved and led to the emergence of the flash crashes.

Innovation has been widely researched since the seminal works of Schumpeter (1934). However, the process of how innovations emerge and are managed is a perpetual issue. Innovation can be incremental (it presents minor improvements) or radical (it is new to the market or new to the company) if it refers to a product or service from a company's perspective; it can be disruptive or non-disruptive if it refers to a technology in a given market.

Disruptive innovation generally emerges from a technological niche that is underestimated or even ignored by the mainstream companies operating in an industry.

In this paper, we define a disruptive innovation, in line with Christensen (1997, 2006), as an innovation that disrupts the current market by serving a market segment that was not initially considered by the established firms, that disrupts the dominant configurations, creates new values that leads to changes to existing markets, and that establishes new working practices.

This technology starts as a radical innovation, and then, building on a value network, subsequently captures the market of the mainstream technology and becomes dominant, moving into a phase of incremental innovations. For a large part of the literature, a disruptive innovation is a technology that changes the performance metrics along which it competes (Daneels, 2004; Pinkse, Bohnsack, and Kolk 2014) or it changes the business models of the firms in the market (Habtay 2012).

Building on this literature, when they first emerged, financial algorithms, in line with Christensen (1997, 2006, 2009), created new values and led to changes to existing, and the creation of new, financial practice. Like many successful innovations, the financial algorithms and market subsequently evolved incrementally. However, in the development of the new incremental innovations, the values associated with the initial disruptive innovation (the initial conception of financial algorithms) were forgotten with detrimental effects. These detrimental effects can be described as epistemological consequences of the disruptive innovation. When conceived in this way, new insights regarding the consequences (flash crashes) can also be reconceptualized. This could lead to new tools to manage the events.

The question posed in this paper is, how can flash crashes be epistemologically reconceived? We propose that flash crashes are analyzed as a disruptive innovation. This allows us to determine their value, episteme and epistemology, and the practices associated with them.

Although there are various epistemic and regulatory alternatives that did emerge following the financial crisis, including greater use of complexity theory (Battiston et al. 2016) and macro- prudential regulation (Claessens, Ghosh, and Mihet 2013), neither are adequate to prevent 'flash crashes'. They have emphasized greater attention to the design and holistic shape of the financial economy, and a recognition that it obeys patterns and logics that are not reducible to individual rationality. In line with these efforts, we propose an epistemic alternative that enables regulators to find 
alternative solutions to the current practice of switching-off the market as a result of a flash crash. We acknowledge the explorative nature of this paper articulating the epistemological problem that the occurrence of flash crashes generates. In this perspective, the objective of this paper is not to demonstrate beyond a reasonable doubt but rather to suggest a plausible direction to deal with knowledge related to flash crashes.

First, the notions of disruptive and incremental innovation are described prior to the computerization of the financial markets, separating computerization into two movements based on the definition of disruptive innovation, in order to analyze the epistemology of financial markets. This allows us to re-conceptualize financial innovations as a disruptive technology. The first movement is associated with the automatization of financial recording and pricing activities, and the second with the automatization of trading. This distinction enables us to demonstrate how an extension of a disruptive innovation (automization of financial recording) through incremental innovation (automization of trading) generated side effects as a result of contradictions with the episteme and principles that initially shaped the disruptive innovation.

In light of these movements, we discuss the organizational changes caused by computerization in financial markets and the epistemic consequences of such side effects. We suggest that the organization of disruptive practices must be combined with a disruptive approach in terms of knowledge, in order to think 'outside the box to get inside the black box' and prevent latent effects. By combining the notion of disruptive innovation with a more critical approach to the analysis of innovations in financial markets, we analyze the epistemological dimension of financial innovation, which is emerging.

In conclusion, we emphasize the necessity to extend the epistemological dimension of financial innovation. To support this epistemological turn, new approaches to financial innovation must be identified. In this vein, an example that could contribute to the debate is presented, namely, design theory - which addresses decision-making based on the analysis of an abductive reality, in which the collective decision makers, constituted by computers and regulators, expand concepts and work in the epistemic dimension of the unknown rather than the known. This type of approach could facilitate a better understanding of the unimagined and unintended consequences of financial innovation.

\section{Disruptive Innovation}

In the innovation literature, it is established that there are different types of innovation. For example, innovation can be: incremental or radical if it refers to a product or service from a company's perspective; and disruptive or non-disruptive if it refers to a technology in the marketplace. While radical innovation is a way of thinking about innovation as a source of competitive advantage for the firm (Verganti 2009), disruptive innovation is a way of thinking about innovation-driven growth in the market rather than at the firm level (Christensen, Raynor, and McDonald 2015). Since our study focuses on the technological development of financial markets, namely the computerization of financial markets that disrupted the previous marketplace, we are referring to the literature on disruptive innovation. Yet, the nature of disruptive innovation is contested, igniting academic (and non) 
debates about the antecedents and constitution of disruptive innovation (e.g. Christensen 2006; Christensen and Overdorf 2000; Christensen, Raynor, and McDonald 2015; King and Baatartogtokh 2015; Markides 2006), although there is not a general agreement on the causes. In a large part of the literature, a disruptive innovation is a technology that changes the performance metrics along which it competes (Danneels 2004; Pinkse, Bohnsack, and Kolk 2014) or it changes the business models of the firms in the market (Habtay 2012). Disruptive innovation emerges from a technological niche that is usually underestimated by the mainstream. This technology, building on the value network, subsequently captures the consumers of the mainstream technology and becomes dominant. The theory has been analyzed from a variety of other angles such as industrial competition(Christensen and Bower 1996), strategic decision-making (Ansari, Garud, and Kumaraswamy 2015), managerial experience and leadership (King and Tucci 2002; Tellis 2006) and the effects of the innovation on mainstream and customers (Govindarajan, Kopalle, and Danneels 2011).

A disruptive innovation is typically a novel innovation that disrupts the current market by serving a market segment that was not initially considered by the established firms but develops to eventually dominate the overall market, disrupting the dominant configurations (Christensen 2006; Christensen and Raynor 2013). The changes in the market's configuration pose dilemmas for both incumbents and new entrants, and possibly changing the competitive environment (Ansari, Garud, and Kumaraswamy 2015), and has a higher probability of succeeding in the market if it is vertically integrated and creates value through its network (Christensen 1997). King and Tucci (2002) add that new entrants might triumph not only because they are part of an integrated value network but also if they have previous managerial experience. They argue that if managers have experience in previous markets, there is an increased probability that their firm will enter a new market, which results in an increase in value. Christensen (2006) disagrees with these findings, arguing that managers running successful companies can become prisoners of their own success, focusing on exploitation rather than exploring new technology.

A famous example concerns the semiconductor industry (Christensen 1997).

Semiconductors had a disruptive effect on the computer industry, and in this context, Intel was able to disrupt the market transforming itself from being a small company into a global player. Intel was launched in 1969, and its business was based on innovative development of metal-on-silicon (MOS) technology to produce the first dynamic random access memory (DRAM) integrated circuits. However, the DRAM market began decaying between 1978 and 1986 under the heavy Japanese semiconductor manufacturers competition, and Intel was able to successfully transform itself from a second-tier DRAM company into the leader of the microprocessor manufacturer. Intel was producing both DRAM and microprocessors, and whilst it understood that profits from DRAM (mainstream industry) were decreasing, the microprocessors were increasing (emerging industry). Intel developed the first microprocessor as an experimental venture for a Japanese calculator manufacturer. However, the project was terminated and Intel's engineering team convinced their executives to purchase the patent from the calculator manufacturer (as Intel was a supplier of the technology). Not seeing the value of it, the manufacturer sold the IP: microprocessors were disruptive technologies when they first emerged (Christiansen, 1997). Although at the 
beginning, their performance was not optimal, they were small, simple, with affordable logic and computation in new applications. Intel senior management focused their attention into the DRAM production, whilst the company's middle managers decided to allocate resources to the research and development for the microproces- sors, which were then produced for IBM's first personal computers. This completely changed the computer industry: the microprocessors outperformed the DRAM, and they became the new standards, making Intel a global player and forcing forcing the DRAM productions out of market.

In another well-known example of disruptive innovation we consider Kodak but in contrast to success we consider failure. Kodak was one of the most successful global companies; however, it filed for bankruptcy protection in 2012, sold off its patents and re-emerged in the market in 2013; in 2016 the market capitalization was worth less than $\$ 1$ billion. Kodak's core business concerned selling film, and with the advent of digital cameras, cellphones disappeared. Digital photography is a completely new way of capturing, sharing and storing pictures, and Kodak failed to react to it. Kodak understood that the new technology was emerging, but its management was rigid and failed to react to the transformation. Interestingly, the first digital camera was developed in Kodak (Anthony 2016). The camera was conceivably big, slow (it needed $20 \mathrm{~s}$ to take a picture), low quality, difficult to see (it needed to be connected to the television), but it had a disruptive potential. Kodak invested in it, trying to match the performance of the traditional film, although initially it mismanaged the investment by trying to achieve technical performance rather than focusing its efforts in the simplicity of digital; eventually, it managed to get a strong market position by extending the pictures business from cameras to computers (Anthony 2016). However, the disruption that Kodak failed to see was not in the technology, but in the new business models of photo sharing with Facebook and Instagram: online photo sharing has become the new business, not a way to sell printed photos. Kodak was still considering itself a film production company, rather than a player on the digital market.

Since these cases were analyzed historically, recent discussions on disruptive innovation are centered on questioning whether the theory can be used for predictive purposes (e.g. Christensen 2006; Danneels 2004), or if it is valid mainly ex-post. However, a pressing question is: how can organizations manage knowledge when disruptive innovation arises (e.g. Christensen, Grossman, and Hwang 2009), which is a relevant question in the financial market.

Therefore, the next section details how the disruptive technological innovation of the computerization of financial markets emerged and how it has been incrementally extended through an algorithmization of markets. Our analysis of the technological innovations financial market is an ex- post analysis, and we identify the moment and movements that lead to a disruption, and how the new technology changed the configuration of the marketplace.

The Computerization of Financial Markets and the Disruptive Innovation in Finance

By computerization, we refer to the fact that each financial marketplace had been equipped with an electronic trading platform. Technically, such a platform is an 
automated market which exercises some or all of the following functions:

electronic order routine (the delivery of orders from users to the execution system), an automated trade execution (the transformation of orders into trades), an electronic dissemination of pre-trade (bid/offer quotes and depth) and post-trade information (transaction prices and volume data).(Committee on the Global Financial System, 2001, cited in Schinckus [2008, 1080])

The computerization of financial transactions disrupted the organization and functioning of financial markets. Indeed, this new way of organizing exchanges revolutionized the financial industry and led all stakeholders to adapt themselves to a new 'screen sociability' (Knorr-Cetina 2006; Muniesa 2007). The interaction of human and non-human technical entities makes it possible for economists to act as social engineers and for economics to perform (Boldyrev and Svetlova 2016). Therefore, this situation paved the way for new forms of analyzing financial markets in terms of sociotechnical construction, in which humans and non-humans interact, create and stabilize the reality (Christiansen and Gasparin 2016). ${ }^{1}$ In the next section, we explain why the automatization was a disruptive innovation, its epistemic regime, why computerization was an incremental innovation, and the epistemic confusion in financial theory that caused the emergence of flash crashes.

\section{The First Movement of Financial Disruptive Innovation: Automatization of Recording/Pricing Activities}

Until the 1960s, 'the development of markets was slow, complex, and not always linear' (Casson and See 2011, 15) in the context of monetary stability and restrictions on international capital movements. In such a setting, the organization of financial markets had been shaped by national considerations in which formal and sometimes informal agreements played a key role (Casson and See 2011). Although the first propositions to automatize financial transactions emerged in the late-1950s (Pardo-Guerra 2012), telephone transactions dominated (Preda 2009). After the abandonment of the Gold standard in the 1970s, the situation radically changed (Jovanovic and Schinckus 2017). The organization of financial markets was standardized to facilitate adoption through the use of a flexible exchange rate regime. In addition, the growing importance of large-scale consumers opened doors to increasing flows of capital across financial markets. This generated demand for automating the dissemination of financial information to all actors operating in the markets. The first internationalization and standardization of financial markets emerged in the 1970s, a decade in which the neoclassical approach of financial economics became the field mainstream (Jovanovic and Schinckus 2013). This theoretical approach based on neoclassical economics provided conceptual guidelines (e.g. perfectly rational agents, no transaction costs, high liquidity) to shape the financial reality (Dupuy 1992; Schinckus 2008). Computers appeared, at that time, to be the best way to create a perfect market, as defined in finance textbooks.

In the 1970s, the new role for information and telecommunication technology 
emerged: to disseminate financial information. This disrupted the financial market. The subsequent decade experienced a rapid growth in the importance of computational tools for recording financial transactions. During this period, while the dissemination of information and recording financial transactions were automatized, the execution of transactions was dominated by human interven- tion (Liu 2012).

Christensen(1997) establishes that a disruptive innovation is supposed to have some specificity and generate consequences for the ecosystem within which it has been developed: 1) the development of vertical integration; 2) emphasis on the value network; 3) the creation of a new management experience; 4) the use of a deductive logic to develop the innovation; and 5) the use of a normative logic to justify the innovation. All these characteristics can be observed in financial marketplaces after their computerization. By reducing the number of intermediaries and, consequently, the transaction costs, algorithms offered a particular vertical integration of financial transactions. This process eased access to capital for a higher number of potential investors, increasing, therefore, the atomicity of the market. The interconnectivity of users and the use of information technology increased the network value on the financial markets where (potentially) everyone could be informed in real time about transactions executed on markets. All data related to these interactions were automatically recorded and generated a huge amount of information that was quasiinstantaneously analyzed by algorithms. Although these algorithms were automatized, they belonged to financial companies and this automatization of trading activities generated new managerial and organizational experiences for financial markets, that is, new forms of sociability and new investment strategies. Thus, algorithms enacted a different form of market (Mirowski 2002).

Even if we do not embrace this perspective, let us mention Pardo-Guerra (2012) who claimed that algorithms were constructed to be rational and detect instantaneously all potential situations of profits on the markets:

Automation is a project informed by the normatives and politics of efficiency, shared by market participants, regulators and technologists(Pardo-Guerra 2012, $573)$.

The knowledge structuring the implementation of algorithms refers to the concept of the perfect market derived from neoclassical economic theory, which resulted from the desire of financial authorities to make the markets more efficient. According to this theory, if information was available to everyone, algorithms could make financial markets fairer through their instantaneous actions to displace information, guaranteeing that the process of giving value results from a generalized rational process of profit-seeking. In this context, computers appear as the appropriate tools to build a perfect market, as stated by Pardo-Guerra (2012):

Technology is not only a solution to the cost-benefit challenges of economic competition, importantly, it is framed as a worthy element that will make markets more transparent, effcient, and fairer. Technology is, in a sense, the means for the realization of an ideal (and ideological) marketplace.(PardoGuerra 2012, 573) 
Algorithms originally focused on the recording/computation of financial prices (Muniesa 2000). This process deeply changed the market environment since it increased the cooperative tensions between actors. More precisely, the continuous quotations (automatic pricing process) combined with the systematic tracking of all transactions generated competition, implying simultaneous strategies for implicit cooperation and competition between actors. The systematic public recording of data was declared to offer a transparent benchmark for the evaluation of all companies leading them to find a balance between the general trend (i.e. implicit cooperation) and making a difference on the market by changing their behavior. In this first move, technology changed the episteme (Millo and Schinckus 2016), and in reaction, companies adjusted their behavior by developing more data-oriented strategies trying to detect (or create) the trend at its beginning (rather than following it). Such an evolution of behavior led to a new structure of financial markets that appears to be more and more in line with the norm of an effcient idea promoted by financial authorities.

This first movement gradually evolved into the second movement, which we call algorithmization of financial trading. In this movement, human decisions have been substituted by trading algorithms able to deal with automatic transactions, thus human actors were not required to actively intervene in the market. We investigate further this second movement in the following section.

\section{Second Movement: Automatization of Trading Activities}

Rapidly, the use of computation has been extended to the stock pricing process since analysts began to develop computational programs to price financial assets. This progressive evolution led, 10 years later, to what we called the algorithmization of financial markets, as Pardo-Guerra (2012) explained:

The consolidation of automated trading - visible in some recent trends in the use of computers systems that automatically create orders and submit them to the market without direct human intervention - was the product of developments that occurred primarily in the 1990s and early 2000s(PardoGuerra 2012, 578).

This algorithmization of financial marketplaces significantly changed the organization of the markets but also the financial reality, since

[T] echnology is another force that has changed the operation and structure of international financial markets. Information and telecommunications technologies have greatly increased the speed with which information is processed and disseminated. Around the world, market participants are bombarded with a plethora of information and a cacophony of opinions, reports, and rumours, much of which is communicated by computers (MacKenzie 2006, 26).

Algorithms were developed to make decisions, which exaggerated the speed of changes: the relation between analysts and their computers, to the point that they gave 
a meaning to the world through the screens with which they interacted (Knorr-Cetina and Bruegger 2002), and provided a personality to the screen (Lepinay and Rousseau 2001; Reeves and Nass 1996). Indeed, the oral negotiations were replaced by a more abstract screen sociability because traders only interacted via their computer screens (Godechot 2001). Algorithms changed the configuration of the market-place, as artificial traders (the algorithms) became able to identify agents authorized to be part of a transaction and could recognize which bids and offers needed to be taken into account, and the way of matching them (Gode and Sunder 1993; Mirowski 2002). This not only changed the modes of working, but also changed the configuration of the market enactment (Mirowski 2002): firms that used to be dominant in the market (such as the stockbroker firms) had been replaced by computers, displaying a rapid growth in e-commerce and the automation of financial markets (e.g. Domowitz and Wang 1994).

Using the disruptive innovation framework, we could claim that the interconnectivity of users and information technology increased the network value on the financial markets, since everyone could be informed in real time about the transactions being executed on and by the markets. To ensure this technical aspect, humans have been substituted by computers. All data related to these interactions are automatically recorded and quasi-instantaneously analyzed by algorithms.

However, this was not a disruption, but an incremental innovation compared to the previous breakthrough. In fact, it extended what the algorithms could do, making them smarter and faster; it created some changes (e.g. the traditional stockbrokers were increasingly not competitive), but it did not reconfigure all of the value chains.

Incremental innovation meant that incremental changes had been introduced, but the concept remains largely the same (Buganza, Dell'Era, and Verganti 2009). This means that although there is an innovative feature in the automatization of financial transactions, it is just incremental. This situation actually does not result from a new epistemology but rather completes the reification (initiated by the first movement) of a very well-known set of assumptions made by economists about financial markets based on Malkiel and Fama (1970): a perfect market in terms of organization (evoked in the previous section) on which perfectly rational agents (algorithms) operate (second movement). In this context, computers and algorithms follow a perfect rationality to identify the arbitrage opportunity and to make the 'right decision' quicker than human beings can. The theoretical argument behind this computerization refers to the necessity to exploit all arbitrage opportunities in order to bring equilibrium to financial markets (Jiang, Tang, and Law 2002).

The development of computerized power paved the way to a two-step materialization of the notion of perfectly competitive markets. This approach to computerizing financial markets did not result from the potential reality (i.e. efficient markets do not exist) but it shaped the reality. This process implies an interesting technique of developing knowledge: in opposition to the classical Popperian (Popper 1965) mode of science in which models are usually adjusted to improve their consistency with reality, financial computerization appears to transform reality to make it closer to theory. Models in science raise semantic, ontological, epistemological and methodological questions, ${ }^{2}$ and they can be a representation of a selected part of the world or represent a theory by interpreting laws and axioms. 
In this case, the financial models did not only represent nor interpret the laws of the markets but created a performative epistemology: computerization gave the opportunity to adapt financial reality to the original theoretical model ('efficient market'). This ideological evolution tended to use the computerization process as a reification of the dominant financial theoretical approach by reducing the room for pluralism in finance. Indeed, if financial markets could have been shaped in accordance with the theoretical framework enhanced by financial scholars, there was no other potential interpretation. However, as demonstrated in the shared epistemology of formalism and substantivism, the validity of the theory depends upon an observation of the facts that it serves to anticipate (Çalışkan and Callon 2009). This means that in order to grasp 'the economy', we have to look for that which is 'economic'. This reification of theory tended to forget that all knowledge refers to a specific imaginary way of thinking about the reality that, once formalized in a computer program, transformed social relations/interactions by generating unanticipated situations (Muniesa 2000).

Automatic trading is considered to make real markets closer to the financial authorities' idealized conception of the effcient market. In this vision, technological innovation is envisaged to create a virtual market closer to the textbook idea of the 'perfect market'. However, as we will detail in the following section, the extension of the automatization of the recording/pricing process to the automatization of the trading process generated unintended effects that are in complete opposition with the theoretical principles justifying the initial innovation.

\section{The Emergence of the Flash Crash and Its Epistemological Incomprehension}

On Thursday 6 May 2010, the Dow Jones Industrial Average plunged about 9\% in less than $5 \mathrm{~min}$. This fall was due to 'the combined selling pressure from the sell algorithm' (US SEC, 2010), which generated a 'hot-potato' volume effect by quickly buying and reselling contracts. According to a Securities and Exchange Commission (SEC) report (U.S. Securities and Exchange Commission and the Commodity Futures Trading Commission 2010), more than 27,000 contracts ( $49 \%$ of total trading volume) were traded on the market within a 14-s period, between $2 \mathrm{~h} 45: 13$ and $2 \mathrm{~h} 45: 27$.

Because algorithms have been created to react to news and events faster than human eyes can scan them, an unforeseen situation occurred in which half of the market was traded in $15 \mathrm{~s}$. This gave rise to a very rapid and deep fall, called a 'flash crash'. A large part of the American economy (represented by the Dow Jones Industrial Average [DJIA] index) lost a significant percentage of its value in a few milliseconds. Extreme variations and crashes are common in finance (Kindleberger 1989), but in the past, they were the result of human behaviors and developed over several days. In contrast, flash crashes appear in a few seconds because they do not result from human actions: this kind of crash results from computerized excitement of the market by algorithms, which create a loop effect in buying and selling trends, generating a sharp fall in security prices. We can observe the significant decrease in the index, combined with a significant trade volume, meaning that algorithms were operating simultaneously within a very short period of time, which created a paradoxical situation in which we had a market without referent (no economic justification) or trader (automated trade). The fall in security prices in Dow Jones on 6 May 2010 also had a negative effect in other markets; for example, analysts in the New York Stock 
Exchange(NYSE) observed a similar flash crash on the same day. This was the first one, and since then others followed as explained in the preamble. One could claim that the market had quickly returned back to its 'normal level', but the real money was lost in that 15-s crash (Madrigal 2010).

How did that happen? Actually, the occurrence of flash crashes is related to the computerization of financial markets that we explained in the previous sections. More precisely, what we called the second movement that computerized the decision-making process led to the emergence of automatic trading. This evolution resulted from the idea that computers can act more rationally and quicker than human beings. This perspective supports the assumption according to which the market is effcient when all agents are perfectly rational and seeking profit maximization. This assumption is theoretically (deductively) justified in the existing financial literature (Fama 1965; Malkiel and Fama 1970), but its extension might be faced with the irrational/behavioural biases of human beings. In this context, the development of automatic financial trading through computers can, therefore, ensure the implementation of perfectly rational (algorithmic) decisions. However, the implementation of this statement in financial reality might be more complex than expected because the reification of the concept of effciency did not necessarily generate all of the deductive consequences that were theoretically inferred from this hypothesis. Although automatic algorithms are supposed to increase the profitseeking process, their generalization within investment behaviors led to a new kind of flash crash that was not anticipated, at least from a theoretical point of view. Thus, the automatization of the profit-seeking process would have required more creative knowledge to develop alternatives to the potential side-effects of technological disruptive innovation. Such a situation in which new phenomena (i.e. flash crashes) emerge calls for a diversification of financial knowledge. There is a need (see Lagoarde-Segot 2016; Schinckus 2017) to diversify our way of dealing with financial knowledge.

The algorithmization of trading is based on an established, taken-for-granted, financial epistemology according to which, when all agents act rationally and seek profit, the market is more efficient. This is not the case showed by flash crashes since perfectly rational agents generated an irrational situation. Flash crashesinvited stakeholders to realize that knowledge, which materialized from algorithms, must not be taken for granted (Slavin 2011). As discussed above, the traditional financial epistemology failed in understanding the complexity of algorithms and in exploring the knowledge that was created as a result of the disruptive innovation (algorithmization of profit- seeking). Thus, we think it is important to find alternative ways of creating, managing and reflecting knowledge. Actually, disruptive innovation should go hand in hand with a disruptive approach in terms of knowledge to eventually figure out some potential unexpected effects of innovation. In fact, in the case of algorithms, they have generated unexpected consequence 
manifested in the flash crash that are 'clearly visible in moments of breakdown, failure or other forms of trouble' (Neyland and Möllers 2016, 1).

More specifically, the origin of flash crashes is commonly attributed to a computerized loop- effect generated by the combined decisions of automatic algorithms that are detecting some anomalies which are interpreted as problematic, and the algorithms consequently decide to act on the market based on their inscribed decision-making process. When they detect anomalies caused by other algorithms, they sell stock at an inhuman pace, causing an immediate crash in the market. The first reported flash crash (6 May 2010) erased USD 862 billion from the stock market value within a couple of minutes (Yiu 2014), which is considered an event of historic proportions, since approximately one trillion dollars evaporated within a few minutes, when the Dow Jones Industrial Average plummeted by over 600 points (approximately $5 \%$ of its total value) between $2.32 \mathrm{pm}$ and $3.08 \mathrm{pm}$ ET (Lange, Lenglet, and Seyfert 2016). Since flash crashes are ascribed to be technological problems, at the moment financial authorities respond through a technical solution to avoid potentially similar situations: they introduced 'circuit breakers' whose goals it is to stop the market when the evolution of financial prices becomes too volatile to have a market with large variations. Circuit breakers have been introduced in automated financial marketplaces to prevent equities from plunging instantaneously. Concretely, this solution stops all trading activities when prices fluctuate beyond a fixed range (usually 10\%). Officially, financial authorities need to preserve the effociency and integrity of the market when unexpected events, such as flash crashes, appear (U.S. Securities and Exchange Commission and the Commodity Futures Trading Commission 2010, note 5, at 11) because a flash crash 'exposed dangerous fractures in our markets' foundations' (Serritella 2010, 434), and can push the stock prices into a downward spiral engendering market chaos (Goldstein 2010). However, switching off the market does not solve the problem, it simply re- emphasizes the conceptual frame that justified the disruptive innovation at the heart of the flash crashes. This situation is particularly relevant because it leads to confusion between deductive/ theoretical reasoning (i.e. perfectly rational agents make the market efficient) and its technical implementation in financial reality. In the absence of alternative ways of thinking and defining flash crashes, financial authorities are also faced with confusion between what financial markets are (technically complex with flash crashes) and what these markets should be (rationally efficient).

In the case of a flash crash, there has been a serious failure in the implementation of the idea and the knowledge of what is a 'perfect market'. Indeed, the algorithmization of trading (based on the efficiency market hypothesis) generated unintended and unimagined situations in which volatility increased suddenly in an illiquid market and wherein rational non-human agents became irrational agents taking positions in a(n) (ill)logical way.

Therefore, in line with the journal's aims of generating new debates, approaches to financial innovation must be reconsidered to prevent latent outcomes like flash crashes. Thus, in light of these new research directions, we provide an example of generating, questioning, and organizing financial epistemology: Design Theory. Design Theory is used in management and engineering to manage disruptive and radical innovations by analyzing the concepts' generation and their development into knowledge. Diverse roads could, of course, be investigated on 
the edge of financial economics and other disciplines. The Design paradigm proposed here may form part of a broader attempt to rethink finance as a kind of complex adaptive system, rather than as a set of efficient markets.

Towards New Epistemological Directions in Financial Innovation: Design Theory By emphasizing the importance of dealing with the unthought-of and unexpected aspects of financial knowledge, this section provides an example of an epistemological approach based on Design Theory. In the context of finance, the emergence of flash crash paves the way to new directions in finance and regulation by suggesting a new reordering of the known and the unknown. Because flash crashes are a counter-example of what financial innovation was suppose to offer, their emergence questions the limits of the unknown in finance, inviting scholars to refine and redesign the implementation of their knowledge, which leads to financial innovation. In the current finance, there is no language to conceptualize the unknown and algorithmization, which is presented and implemented as a context-independent process (whereas it is clearly not).

If analyzed within the dominant orthodox financial mainstream, the phenomenon of the flash crash is still unexplained, which is worrying for the financial markets operating in the post-2008 crisis context in which finance is challenged on different aspects (Gendron and Smith-Lacroix 2015; Lagoarde-Segot 2016). The flash crashes are unexplained because nobody is able to identify the first 'signal of failure' (The Economist, 27 October 2012), as they are self-organizing. This means that the algorithms are designed to learn from the signals that they are receiving from the market, and they adjust their decision-making process based on the models on which they have been set up. Thus, stakeholders vaguely agreed to point to the algorithms as the cause:

The conditions that precipitate the [flash] crash were already embedded in the market's web of causation, a self-organized rapidly evolving structure created by the interplay of high frequency trading algorithms. The flash crash was the birth cry of a network coming to life...

(The Economist, 12 May 2011)

While this example demonstrates that financial innovation necessitates a more reflexive investigation of the knowledge that is emerging through computerization, the financial stakeholders reaffirmed the necessity to find the organization of the market operating on particular explicit (i.e. known) knowledge (efficient market hypothesis). In order to overcome this epistemological problem, Design Theory can provide a new epistemological frame. According to Design Theory, in order to have a working innovative product, new knowledge is required to expand concepts and to reduce the unknown by increasing the known. This epistemological process is based on a dual expansion of concepts: the unknown (such as imagery, fantasy, or desire) and the known (forms of knowledge that could include discovery, experimentation, knowledge acquisition) (Hatchuel et al. 2010), facilitating learning through questioning existing imaginary solutions. Such finance methods require an ability (and the will) of stakeholders to think outside of orthodox financial knowledge. Because Design Theory mainly focuses on context rationalization, this field can offer 
a lot of conceptual tools to question and improve the unthought aspects of financial knowledge.

Design Theory has multiple theoretical lenses (Le Masson, Dorst, and Subrahmanian 2013). Initially developed by Simon (1969), design is a part of artificial science proposing a theoretical and practical way of producing knowledge. The artificial aspect is defined as being 'produced by art rather than by nature; not genuine or natural; affected; not pertaining to the essence of the matter' (Simon 1969, 4). In this perspective, design can potentially be related to all processes producing knowledge and, therefore, to all disciplines, as Simon (1969) proposed:

Design, so construed, is the core of all professional training; it is the principal mark that distinguishes the professions from the sciences. Schools of engineering, as well as schools of architecture, business, education, law, and medicine, are all centrally concerned with the process of design (Simon 1969, 111)

Design requires flexibility, making assertions and inferences on how to interpret the world. Simon uses the word design as a noun and a verb. As a noun, Design means to be artificial, but as a verb, it is used in the context of designing alternative paths for making decisions. In this context, design can be perceived as the development of knowledge referring to an optimal problem-solving process that helps managers/decision makers to identify/define tools for making decisions. Design, therefore, contributes to the transformation of existing conditions into preferred ones, a process of problem-solving that is rooted in the creation of new and useful things.

Table 1. A comparative epistemological framework relating financial logic to Design Theory (inspired by Hatchuel et al. 2010).

\begin{tabular}{|l|c|c|}
\hline Knowledge & $\begin{array}{c}\text { Financial Algorithms: financial } \\
\text { logic }\end{array}$ & $\begin{array}{c}\text { Financial Algorithms: design } \\
\text { epistemology }\end{array}$ \\
\hline Episteme & $\begin{array}{c}\text { Shape the functioning of } \\
\text { the market; } \\
\text { Implement the well-known aspects }\end{array}$ & $\begin{array}{c}\text { Generate unknown possibilities; } \\
\text { expand the unknown situations; } \\
\text { imagine new realities } \\
\text { Unknown and based on } \\
\text { imaginary solutions }\end{array}$ \\
\hline Epistemology & Fixed and a priori & $\begin{array}{c}\text { Design spaces; } \\
\text { context-dependent } \\
\text { rationalization }\end{array}$ \\
\hline Collective & $\begin{array}{r}\text { Efficiency market } \\
\text { hypothesis; context independent } \\
\text { maximization }\end{array}$ & $\begin{array}{c}\text { Designers: computers } \\
\text { and humans }\end{array}$ \\
\hline Design space & Implementerslregulators & Relational \\
\hline $\begin{array}{l}\text { Performance } \\
\text { evaluation }\end{array}$ & Automatized & $\begin{array}{c}\text { Building sustainable advantage } \\
\text { Reality }\end{array}$ \\
\hline
\end{tabular}

In the case of financial algorithms, a Design Theory-based perspective would emphasize the context in which these algorithms are implemented. This focus on the rationalization context provides an interesting conceptual tool for studying all 
potential extensions of knowledge to other financial contexts. If we look at the algorithmization process happening in a design space (Hatchuel, Starkey, Tempest, and Masson 2005), as proposed it could be possible to work on this epistemology that is in crisis. In Table 1, we compare the epistemol- ogy of financial algorithms according to the mainstream financial logic - as it is currently widely accepted, and that of algorithms as a disruptive innovation through the lens of Design Theory. In the Design Theory epistemology, knowledge is used to expand concepts into unknown situations, to imagine new abductive realities, which would be rationalized in design spaces that are context-related. This process could be implemented in the design of self-organizing algorithms, to make them imagine new realities beyond the efficient market - this would include the possibility of flash crashes emerging in unknown situations and take actions to address them. This could facilitate and lead designers and regulators to alternative approaches to addressing flash crashes, not switching them off. The episteme for the design is based on imaginary solutions; therefore, it would go beyond the mainstream model.

While the financial sphere and the implementation of financial algorithms deal with the existing scheme of knowledge ('what has been gathered'), Design Theory might help to stress the variety of regimes ('what else can be gathered') and differences between their modes of existence.

\section{Conclusion}

We suggest that the modes of organizing financial markets mustensure that incremental innovations fit not only with previous versions of an innovation's design but also with its epistemological foundations. We explained that this extension of a disruptive innovation (i.e. automatization of profit- maximizing principle) corresponds to confusion between deductive reasoning and a normative way of thinking surrounding financial markets. Such confusion shows that the implementation of a disruptive innovation requires a disruptive approach at the level of the knowledge that framed the innovation when designed and developed, in order to favor the possibility to think/conceptualize potential unimagined side effects (flash crashes) of the innovation, which could be ascribable to poor organization of the epistemological dimension of financial innovation. The implementation of a disruptive innovation must then be reconsidered alongside its epistemological foundations. In this paper, we have evoked a potential (and original) alternative approach: Design Theory.

In line with recent calls for pluralism, this paper promotes a pluralistic approach to implement- ing finance especially when it comes to reify/materialize knowledge that could lead to future disruptive innovations or prevent the unconceived effect of a disruptive innovation. This discussion is not meant to be conclusive and invites other contributions in this epistemological area to verify the theory and elaborate practical implications for financial authorities.

\section{Notes}

Let us mention the creation of a field called STS (Science Technology and Society Studies) whose major objective is to study the semiotics of materiality (Law and Hassard 1999) without distinguishing a priori between human and non-human actors, 
that are both considered equally important.

https://plato.stanford.edu/entries/models-science/.

\section{References}

Adner, R. 2002. "When are Technologies Disruptive? A Demand-Based View of the Emergence of Competition."

Strategic Management Journal 23 (8): 667-688. doi:10.1002/(ISSN)1097-0266.

Akrich, M., M. Callon, and B. Latour. 2002. "The Key to Success in Innovation Part I: The Art of Interessement."

International Journal of Innovation Management 6 (2): 187-206.

doi:10.1142/S1363919602000550.

Ansari, S. S., R. Garud, and A. Kumaraswamy. 2015. “The Disruptor's Dilemma: TiVo and the US Television Ecosystem."

Strategic Management Journal 37 (9): 1829-1853.

Anthony, S. 2016. "Kodak'S Downfall Wasn'T about Technology." Harvard Business School Cases 1. 01 July 2016

Aoki, M., and H. Yoshikawa. 2007. Reconstructing Macroeconomics: A Perspective from Statistical Physics and Combinatorial Stochastic Processes. Cambridge, UK:

Cambridge University Press.

Battiston, S., J. D. Farmer, A. Flache, D. Garlaschelli, A. Haldane, H. Heesterbeek, C.

Hommes, C. Jaeger, R. May, and

M. Scheffer. 2016. "Complexity Theory and Financial Regulation." Science 35 (6275):

818-819. doi:10.1126/science. aad0299.

Boldyrev, I., and E. Svetlova. 2016. Enacting Dismal Science: New Perspectives on the Performativity of Economics.

New York: Springer.

Borch, C. 2016. "High-Frequency Trading, Algorithmic Finance and the Flash Crash: Reflections on Eventalization."

Economy and Society 45 (3-4): 350-378. doi:10.1080/03085147.2016.1263034.

Bower, J., and C. Christensen. 1995. "Disruptive Technologies: Catching the Wave."

Harvard Business Review 45-53. Buganza, T., C. Dell'Era, and R. Verganti. 2009.

"Exploring the Relationships between Product Development and

Environmental Turbulence: The Case of Mobile TLC Services." Journal of Product

Innovation Management 26 (3): 308-321. doi:10.1111/j.1540-5885.2009.00660.x.

Çalışkan, K., and M. Callon. 2009. "Economization, Part 1: Shifting Attention from the

Economy Towards Processes of Economization." Economy and Society 38 (3): 369-398. doi:10.1080/03085140903020580.

Casson, M., and J. See. 2011. "The Origin and Development of Markets: A Business

History Perspective.” Business History Review 85 (1): 9-37. (Spring).

doi:10.1017/S0007680511000018.

Christensen, C., and M. Raynor. 2013. The Innovator's Solution: Creating and Sustaining Successful Growth. Cambridge, MA: Harvard Business Review Press.

Christensen, C., M. E. Raynor, and R. McDonald. 2015. "What Is Disruptive Innovation?" Harvard Business Review 93 (12): 45-53. December.

Christensen, C. M. 1997. The Innovator Dilemma. Cambridge, MA: HBS Press.

Christensen, C. M. 2006. "The Ongoing Process of Building a Theory of Disruption." 
Journal of Product Innovation Management 23 (1):39-55.

doi:10.1111/jpim.2006.23.issue-1.

Christensen, C. M., J. H. Grossman, and J. Hwang. 2009. The Innovator's Prescription: A Disruptive Solution for Health Care. New York: McGraw-Hill.

Christensen, C. M., and J. L. Bower. 1996. "Customer Power, Strategic Investment, and the Failure of Leading Firms."

Strategic Management Journal 17 (3): 197-218. doi:10.1002/(ISSN)1097-0266.

Christensen, C. M., and M. Overdorf. 2000. "Meeting the Challenge of Disruptive

Change." Harvard Business Review 78 (2): 66-77.

Christiansen, J. K., and M. Gasparin. 2016. "Managing Controversies in the Fuzzy Front

End.” Creativity and Innovation Management 25 (4): 500-514. doi:10.1111/caim.12174.

Claessens, S., S. Ghosh, and R. Mihet. 2013. "Macro-Prudential Policies to Mitigate

Financial System Vulnerabilities."

Journal of International Money and Finance 39: 153-185.

Condliffe, J. 2016. "Algorithms Probably Caused a Flash Crash of the British Pound." MIT Technology Review 1, October 7. Coombs, N. 2016. "What Is an Algorithm? Financial Regulation in the Era of High-Frequency Trading." Economy and

Society 45 (2): 278-302. doi:10.1080/03085147.2016.1213977.

Danneels, E. 2004. "Disruptive Technology Reconsidered: A Critique and Research Agenda." Journal of Product Innovation Management 21 (4): 246-258.

doi:10.1111/j.0737-6782.2004.00076.x.

Domowitz, I., and J. Wang. 1994. "Auctions as Algorithms: Computerized Trade

Execution and Price Discovery.” Journal of Economic Dynamics and Control 18 (1): 29 60. doi:10.1016/0165-1889(94)90068-X.

Dupuy, J.-P. 1992. Liberalisme et justice sociale: Le sacrifice et l'envie. Paris: Hachette. Fama, E. F. 1965. "The Behavior of Stock-Market Prices." The Journal of Business 38 (1): 34-105. doi:10.1086/jb.1965.38. issue-1.

Gendron, Y., and J. H. Smith-Lacroix. 2015. "The Global Financial Crisis: Essay on the Possibility of Substantive Change in the Discipline of Finance." Critical Perspectives on Accounting 30: 83-101. doi:10.1016/j.cpa.2013.09.002.

Gode, D. K., and S. Sunder. 1993. “Allocative Efficiency of Markets with ZeroIntelligence Traders: Market as a Partial

Substitute for Individual Rationality." Journal of Political Economy 119-137. doi: $10.1086 / 261868$.

Godechot, O. 2001. Les traders: Essai de sociologie des marchés financiers. Paris: Editions La Découverte.

Goldstein, M. 2010. “Stock Plunge Raises Alarm on Algo Trading." Reuters Accessed 7 May 2010. http://www.reuters. com/article/idUSTRE64631Y20100507

Govindarajan, V., P. K. Kopalle, and E. Danneels. 2011. "The Effects of Mainstream and Emerging Customer Orientations

on Radical and Disruptive Innovations." Journal of Product Innovation Management 28 (s1): 121-132. doi:10.1111/ j.1540-5885.2011.00865.x.

Habtay, S. R. 2012. "A Firm-Level Analysis on the Relative Difference between Technology-Driven and Market-Driven

Disruptive Business Model Innovations." Creativity and Innovation Management 21 (3): 290-303. doi:10.1111/ caim.2012.21.issue-3.

Hatchuel, A., K. Starkey, S. Tempest, and P. Le Masson. 2010. "Strategy as Innovative 
Design: An Emerging Perspective." In The Globalization of Strategy Research, edited by Baum Joel A. C., Joseph Lampel, 3-28. Emerald Group Publishing Limited. Hatchuel, A., K. Starkey, S. Tempest, and P. Le Masson. 2010. Strategy as innovative design: An emerging perspective. In The Globalization of Strategy Research (Advances in Strategic Management, Vol. 27) edited by Baum Joel A.C., J., Lampel, 3-28. Emerald Group Publishing Limited.

Javier, L.-A., and S. Barton. 2017. Another Bullion Flash Crash Is Testing Traders. Bloomberg. https://www.bloomberg. com/news/articles/2017-07-07/another-bullionflash-crash-is-testing-the-nerve-of-traders

Jiang, G., N. Tang, and E. Law. 2002. "Electronic Trading in Hong Kong and Its Impact on Market Functioning." BIS (Bank for International Settlements) Papers, 12. Jovanovic, F., and C. Schinckus. 2013. "The Emergence of Econophysics: A New Approach in Modern Financial Theory."

History of Political Economy 45 (3): 443-474. doi:10.1215/00182702-2334758. Jovanovic, F., and C. Schinckus. 2017. Econophysics and Financial Economics: An Emerging Dialogue. Oxford: Oxford University Press.

Kindleberger, C. 1989. Manias, Panics, and Crashes: A History of Financial Crises. London: Macmillan.

King, A. A., and B. Baatartogtokh. 2015. "How Useful Is the Theory of Disruptive Innovation?" MIT Sloan Management Review 57 (1): 77.

King, A. A., and C. L. Tucci. 2002. "Incumbent Entry into New Market Niches: The Role of Experience and Managerial Choice in the Creation of Dynamic Capabilities." Management Science 48 (2): 171-186. doi:10.1287/ mnsc.48.2.171.253.

Knorr-Cetina, K. 2006. “The Market.” Theory, Culture, and Society 23 (2-3): 551-556. doi:10.1177/0263276406062702. Knorr-Cetina, K., and U. Bruegger. 2002. "Global Microstructures: The Virtual Societies of Financial Markets." American Journal of Sociology 107 (4): 905-950.

Lagoarde-Segot, T. 2016. "Financialization: Towards a New Research Agenda." International Review of Financial Analysis

51 (C): 113-123. doi:10.1016/j.irfa.2016.03.007.

Lange, A. C., M. Lenglet, and R. Seyfert. 2016. "Cultures of High-Frequency Trading: Mapping the Landscape of Algorithmic Developments in Contemporary Financial Markets." Economy and Society 45 (2): 149-165.

doi:10.1080/03085147.2016.1213986.

Law, J., and J. Hassard. 1999. Actor Network Theory and After. Oxford: Blackwell. Le Masson, P., K. Dorst, and E. Subrahmanian. 2013. "Design Theory: History." State of the Arts and Advancements. Res Eng Des 24 (2): 97-103.

Lenglet, M., and M. Joeri. 2016. "Squaring the Speed of Light? Regulating Market Access in Algorithmic Finance."

Economy and Society 45 (2): 201-229. doi:10.1080/03085147.2016.1213080.

Lepinay, V., and F. Rousseau. 2001. "Les trolls sont-ils incompétents? Enquête sur les financiers amateurs." Politix 13: 73-97. doi:10.3406/polix.2000.1120.

Liu, A. 2012. "When Wall Street Robots Go Rogue, Banks Lose \$10 Million a

Minute." Motherboard blog. https:// motherboard.vice.com/en-

us/article/wnnpwx/wall-street-robots-go-rogue-lose-10-million-a-minute Long, S. 2016. "Flash Crash Bang Wallop." The Economist.

https://www.economist.com/blogs/freeexchange/2016/10/ money-talks-0 
MacKenzie, D. 2003. "Long-Term Capital Management and the Sociology of Arbitrage." Economy and Society 32 (3): 349-380. doi:10.1080/03085140303130. MacKenzie, D. 2006. An Engine, Not a Camera: How Financial Models Shape Markets. Cambridge, MA: MIT Press. Madrigal, A. 2010. "Market Data Firm Spots the Tracks of Bizarre Robot Traders." The Atlantic 4: 119-121.

Malkiel, B. G., and E. F. Fama. 1970. "Efficient Capital Markets: A Review of Theory and Empirical Work." Journal of

Finance 25 (2): 383-417. doi:10.1111/j.1540-6261.1970.tb00518.x.

Markides, C. 2006. "Disruptive Innovation: In Need of Better Theory." Journal of

Product Innovation Management 23 (1): 19-25. doi:10.1111/jpim.2006.23.issue-1.

Millo, Y., and C. Schinckus. 2016. "A Nuanced Perspective on Techne and Episteme in Finance.” International Review of Financial Analysis 46: 124-130.

doi:10.1016/j.irfa.2016.04.001.

Mirowski, P. 2002. Machine Dreams: Economics Becomes a Cyborg Science. Cambridge, UK: Cambridge University Press. Muniesa, F. 2000. "Un robot walrasien: Cotation électronique et justesse de la découverte des prix." Politix 13: 121-154. doi:10.3406/polix.2000.1122.

Muniesa, F. 2007. "Market Technologies and the Pragmatics of Prices." Economy and Society 36 (3): 377-395. doi:10.1080/03085140701428340.

Munro, R. 2001. "Calling for Accounts: Numbers, Monsters and Membership."

Sociological Review 49 (4): 473-494. doi:10.1111/1467-954X.00343.

Neyland, D., and N. Möllers. 2016. "Algorithmic IF...THEN Rules and the

Conditions and Consequences of Power."

Information, Communication \& Society 20 (1): 45-62.

doi:10.1080/1369118X.2016.1156141.

Pardo-Guerra, J. P. 2012. "Financial Automation, Past, Present and Future." In The Oxford Handbook of the Sociology of Finance, edited by K. Knorr Cetina and A. Preda, 567-587. Oxford, UK: Oxford University Press.

Pinkse, J., R. Bohnsack, and A. Kolk. 2014. "The Role of Public and Private Protection in Disruptive Innovation: The Automotive Industry and the Emergence of Low-Emission Vehicles." Journal of Product Innovation Management 31 (1): 43-60. doi:10.1111/jpim.2014.31.issue-1.

Popper, K. R. 1965. Conjectures and Refutations: The Growth of Scientific Knowledge. New York: Basic Books.

Preda, A. 2009. Framing Finance: The Boundaries of Markets and Modern Capitalism. Chicago: University of Chicago Press.

Reeves, B., and N. Nass. 1996. The Media Equation: How People Treat Computers, Television, and New Media like Real People and Places. Cambridge, UK: Cambridge University Press.

Schinckus, C. 2008. "The Financial Simulacrum: The Consequences of the Symbolization and the Computerization of the Financial Market." Journal of SocioEconomics 37 (3): 1076-1089. doi:10.1016/j.socec.2006.12.067.

Schinckus, C. 2017. "An Essay on Financial Information in the Area of Computerization.” Journal of Information Technology 33 (1): 9-18. doi:10.1057/s41265-016-0027-1.

Schinckus, C. 2018. "Pataphysics of Finance: An Essay of Visual Epistemology." Critical Perspectives on Accounting 52 (C): 57-68. doi:10.1016/j.cpa.2016.08.003. 
Schumpeter, J. A. 1934. The Theory of Economic Development an Inquiry into Profits, Capital, Credit, Interest and The Business Cycle. Cambridge, MA: Harvard University Press.

Senior Supervisors Group. 2015. "Algorithmic Trading Briefing Note.” https://www.newyorkfed.org/medialibrary/ media/newsevents/news/banking/2015/SSG-algorithmic-trading-2015.pdf Serritella, D. 2010. "High Speed Trading Begets High Speed Regulation: SEC Response to Flash Crash, Rash." Journal of Law, Technology and Policy 10: 433-444.

Simon, H. A. 1969. The Sciences of the Artificial. Cambridge, MA: MIT Press. Slavin, K. 2011. "How Algorithms Shape Our World." http://www.ted.com/talks/kevin_slavin_how_algorithms_shape_our_world.html Souleles, D. 2017. "Something New: Value and Change in Finance." Journal of Cultural Economy 10 (4): 393-404. doi:10.1080/17530350.2016.1261257.

Tellis, G. J. 2006. “Disruptive Technology or Visionary Leadership?” Journal of Product Innovation Management 23 (1): 34-38. doi:10.1111/jpim.2006.23.issue-1.

U.S. Securities and Exchange Commission and the Commodity Futures Trading Commission. (2010). "Findings regarding the Market Events of May 6, 2010." (Original 30 September) Archived from the original on 10 October 2010. Verganti, R. 2009. Design-Driven Innovation: Changing the Rules of Competition by Radically Innovating What Things Mean. Boston, MA: Harvard Business School Press. Yiu, E. 2014. "Brokers Remain Doubtful about Hong Kong Stock Exchange's Need for Circuit Breakers." South China Morning Post February 1: 6-8. 